\title{
FRAGMENTOS DE UM DISCURSO SOBRE A FORMA-AÇÃO DO ATORPROFESSOR
}

Esse artigo apresenta alguns fragmentos comentados da tese que desenvolvi entre 2008 e 2011. A reflexão principal do discurso da tese está pautada pelas interferências das intimações do imaginário na interação entre forma e ação no trabalho do atorprofessor. É a tensão entre forma e ação que se configura como possibilidade de reeducação do sensível e cria condições para um duplo actante da cena pedagógica explicitado pelo neologismo atorprofessor. Este, por sua vez, foi cunhado por meio da aproximação das duas funções buscando problematizar a própria presença do teatro na escola. As intimações do imaginário, percebidas em experimentos poéticos como metodologia de pesquisa, é o que norteia a polarização da presença do atorprofessor no contexto escolar, mas também no meio teatral enquanto espaço pedagógico.

Palavras-chave: Palavras-chave: Intimações do imaginário; reeducação do sensível; forma-ação do atorprofessor.

Abstract

This article reviews and presents some fragments of the thesis I developed between 2008 and 2011. The main reflection of the discourse of the thesis is guided by the interference of the imaginary sub poems in the interaction between form and action in the work of actorprofessor. It is the tension between form and action that is configured as a possibility for the sensitive rehabilitation and creates conditions for a double actant explicit teaching of the scene by the neologism actorprofessor. This, in turn, was coined by approximating the two functions seeking to question the very presence of the theater in school. The subpoems of the imaginar $\mathrm{y}$, perceived as poetic experiments in research methodology, is what drives the polarization of the presence of actorprofessor in the school context, but also $\mathrm{n}$ the theater as a pedagogical space. 
É preciso reabrir o campo das imagens primitivas que talvez tenham sido os centros de fixação das lembranças que permaneceram na memória.

Gaston Bachelard

\section{Fragmento 01: o contexto}

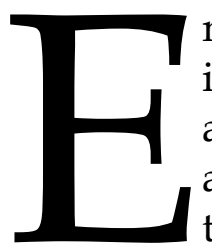

$m$ "As intimações do imaginário ea forma-ação do atorprofessor: cartas sobre a reeducação do sensível", tese defendida no início de

2011 no PPG em Educação da Universidade Federal de Pelotas apresentei uma série de cartas que explicitam a totalidade do trajeto de pesquisa. Essas cartas têm como pano de fundo dois campos: o teatro e o imaginário.

Do campo do teatro dialoguei principalmente com dois autores: Stanislavski e Grotowski. Do campo do imaginário também dois autores: Gilbert Durand e Michel Maffesoli. As poéticas teatrais de Stanislavski e de Grotowski serviram de referencial teórico do campo teatral, mais especificamente três dos mitemas presentes nessas poéticas, a saber: 1. o trabalho do ator sobre si mesmo; 2 . a aprendizagem em grupo; e 3. a ação física como elemento estruturante da cena. As teorias do campo do imaginário serviram de lente para ler as poéticas teatrais enquanto estruturas antropológicas do imaginário. Nessas estruturas identifiquei a presença de elementos míticos, além de pensá-las enquanto rituais sociais constituintes do trajeto antropológico dos alunos envolvidos.

A pesquisa em si ocorreu com três estudantesdeteatroetevecomometodologia a confecção de experimentos poéticos. A ideia básica dos experimentos poéticos é

**** veio em RTF e não tem notas de rodapé o exercício de cena dando visibilidade aos seus elementos constitutivos.

Diante desse escopo teórico, a metodologia buscou, ao dar visibilidade aos elementos componentes da cena, possibilitar que tanto os atores quanto espectadores participassem da cena em sua forma mais primitiva: a do teatro como lugar de onde se vê/percebe. Com isso, os alunos sujeitos da pesquisa passaram a exercer, além da função de ator, a função de professor e nisso ficou instituído o neologismo atorprofessor - um duplo actante.

Ao longo da pesquisa foram confeccionados dez experimentos poéticos com o intuito de verificar como as intimações do imaginário interferiam no processo de formação por meio da interação entre forma e ação de cada um dos alunos na condição de atoresprofessores.

As cartas sobre a reeducação do sensível, produto final da pesquisa, foram destinadas aos próprios alunos como um fechamento ao trajeto de pesquisa.

\section{Fragmento 02: sobre as intimações do Imaginário}

Entender a ação das intimações do imaginário pressupõe aceitar o fato de que a humanidade tem um reservatório único de imagens, mas que estas se renovam ciclicamente. Usei, para explicar como as intimações do imaginário agem no cotidiano, um exemplo da literatura. Mais especificamente, remeti os leitores a um texto de Andersen (1997), “A pequena vendedora de fósforos".

Nesse texto uma menina está na rua, em uma noite de natal em que o frio está intenso, vendendo fósforos. Todos os que passam por ela estão impregnados de suas imagens particulares do natal. Em função dos ensimesmamentos nas imagens pessoais de cada transeunte a menina não é percebida. Essa menina para diante de uma casa em que se pode ver uma família reunida em torno das comemorações do 
natal: há uma sala enfeitada com árvore colorida, uma mesa farta, uma lareira. A menina, ao entrar em contato com as imagens da família em festa, reestrutura por meio de uma tensão entre forma e ação, todas as imagens que ela percebe. $\mathrm{O}$ peru dança para ela. A árvore aproximase e quase a abraça. $\mathrm{O}$ fogo a aquece por um instante. Para cada uma das imagens criadas, um fósforo é aceso pela menina. Os fósforos, no entanto, acabam. Só resta à menina uma última imagem. Uma imagem que abarca todas as imagens recriadas com a cena da família do natal: sua avó, a única pessoa que a amara, entretanto, já morta, aparece nas últimas chamas dos últimos fósforos e a toma nos braços. $\mathrm{O}$ sonho criado pela menina, diante da cena de natal, materializa-se: ela recebe o calor de que necessitava. A menina morre nos braços da avó, isto é, morre na imagem dos braços arcaicos da avó. No outro dia é encontrada morta, de frio e de abandono. Todos se comovem. As imagens que estavam impregnadas na véspera do natal já haviam sido substituídas. Os transeuntes já podiam ver outras coisas além de suas próprias imagens, suas representações pessoais.

Evidentemente não fiz nenhuma análise literária. Minha competência é limitada para o assunto e, além do mais, não era o caso. $\mathrm{O}$ que queria que os leitores da tese compreendessem com esse exemplo é o fato de as imagens interferirem constantemente em nosso cotidiano. O exemplo de "A pequena vendedora de fósforos" deixa entrever que, tomados por um conjunto de imagens específicas, os transeuntes pautam-se por elas. Por isso não percebem aquilo que é tão evidente: uma menina faminta e com frio na véspera do natal. $\mathrm{O}$ jogo de imagens, no qual estamos imersos, inibe a sensibilidade para determinadas formas, potencializando-a para outras.

Essa potencialização de conjuntos de imagens precisa, cotidianamente, ser considerada em cada um dos contextos de forma-ação do atorprofessor. Esse é um modo de agir do imaginário: os conjuntos de imagens que estruturam nosso modo de sentir e perceber o que nos rodeia interferem no nosso dia a dia por meio de intimações. Perceber essas intimações é re-ver, re-ouvir o mundo, é em última instância reeducar-se o sensível. O sensível, considerando o movimento e o fluxo de imagens que permeiam nosso cotidiano, precisa ser reeducado constantemente. E essa reeducação passa pelo diálogo com o outro: por uma partilha. Como está posto no texto "A função da arte/1", de Eduardo Galeano:

\footnotetext{
Diego não conhecia o mar. O pai, Santiago Kovadloff, levou-o para que descobrisse o mar. Viajaram para o Sul.

Ele, o mar, estava do outro lado das dunas altas, esperando.

Quando o menino e o pai enfim alcançaram aquelas alturas de areia, depois de muito caminhar, o mar estava na frente de seus olhos. E foi tanta a imensidão do mar, e tanto o seu fulgor, que o menino ficou mudo de beleza.

E quando finalmente conseguiu falar, tremendo, gaguejando, pediu ao pai: - Me ajuda a olhar! (2007, p. 15).
}

O texto de Galeano me ajudou, na pesquisa, a olhar as dimensões do sensível e das intimações do imaginário no jogo social. O que eu estava querendo, enquanto pesquisa, era justamente ampliar esse olhar (no sentido de buscar uma visão ampla, abrangente). Esse texto continha aquilo que pretendia como pesquisador, professor e como artista de teatro: estimular o movimento do sensível.

Os experimentos poéticos tornaram evidente que há um constante movimento do sensível que possibilita que nos desloquemos entre máscaras sociais, isto é, que possibilita que eu me coloque no lugar do outro ampliando a visão que tenho dos contextos. O constante deslocamento para o lugar do outro cria uma efetiva partilha dos contextos. Esse deslocamento impede a eleição "da verdade", favorecendo, com isso, as aprendizagens/ensino. O problema está em não poder definir com exatidão como se dá uma reeducação do sensível, 
pois não há um método, apenas algumas constantes apreendidas no cotidiano da pesquisa. O sensível é movente porque deriva de percepções mais ou menos amplas.

\section{Fragmento 03: a tensão entre forma e ação}

Uma das constantes presentes na tese é o diálogo com poéticas teatrais como formas estruturadas, mas estruturantes do trabalho do ator. Os estudos do imaginário reforçam que é imprescindível o diálogo com imagens do próprio campo anteriores ao nosso tempo.

Com isso cheguei à imagem central da tese: a tensão entre a forma e ação resultando em forma-ação. Essa tensão pode ser compreendida por meio de um procedimento presente nas poéticas de Stanislavski e de Grotowski: a fixação do trabalho de composição do ator em partituras físico-vocais. $\mathrm{O}$ fato de fixar a ação em uma forma estruturada não impede o dinamismo promovido pelas intimações do imaginário. Muito pelo contrário, a forma assegura e contém o movimento, a ação. Nas palavras de Cieslak:

A partitura é como um copo de vidro no qual está uma vela acesa. O vidro é sólido, está ali; você pode confiar. Contém e guia a chama da vela. Porém, não é a chama. A chama é meu processo interior de cada noite. A chama é o que ilumina a partitura. Ilumina o que o espectador vê através da partitura. A chama está viva. Assim como a chama da vela atrás do vidro se move, flutua, se expande, se encolhe; quase apaga e volta a brilhar intensamente, reage a cada sopro de vento, também minha vida interior varia a cada noite, de momento em momento... Começo, cada noite, sem antecipar nada. Esta é a coisa mais difícil de aprender. Não me preparo ensaiando. Não digo: "na vez passada, esta cena era extraordinária, tratarei de voltar a fazê-la". Quero somente estar pronto para o que vier a acontecer. E me sinto pronto para a alçar o voo que poderá acontecer se me sinto seguro na partitura, sei que também quando não sinto quase nada o vidro não se romperá porque a estrutura objetiva, trabalhada por meses, me ajudará. Quando chega a ocasião em que posso arder, brilhar, viver, revelar - então estou pronto porque não o antecipei. A partitura é a mesma, porém cada coisa é distinta, porque eu sou distinto (Máscara, 1994, p. 22 - livre tradução).

A partitura de ações físicas, embora com distinções na sua constituição, é um ponto de convergência entre Stanislavski e Grotowski, pois é a única coisa na qual o ator pode se apoiar, ou melhor, sustentarse, existir.

Em ambos o vidro é a forma; a chama da vela a ação do ator. O que altera são os procedimentos iniciais para a criação teatral. A relação forma-ação institui o que é essencial à criação: a forma assegura a movência natural da ação do ator. A forma é o princípio seguro (apolíneo, diurno), a ação o reagente efêmero (dionisíaco, noturno).

\section{Fragmento 04: o atorprofessor como duplo actante}

O atorprofessor é um duplo actante na mesma medida em que o teatro pode ser considerado espaço privilegiado de formação. Paratanto,é precisocompreender a formaçãonainteração entreaprendizagem e ensino. É a relação que se estabelece entre uma espécie de afastamento do objeto e a aproximação deste que se configura em aprendizagem e ensino, resultando, com isso, formação em um sentido amplo. Nas palavras de G. Gadamer,

[...] o que perfaz a essência da formação não é o alheamento como tal, mas o retorno a si, que pressupõe naturalmente o alheamento. Nesse caso, a formação não deve ser entendida apenas como o processo que realiza a elevação histórica do espírito ao sentido universal, mas é 
também o elemento onde se move aquele que se formou (2004, p. 50).

Esse movimento, isto é, esse deslocamentoqueosindivíduosfazem pode ser compreendida por meio de uma equação em que ensino é um denominador (uma forma) e aprendizagem é um numerador (uma ação). Seria melhor representá-la da seguinte maneira:

aprendizagem

ensino

Essa equação representa, para mim, um jogo entre duas funções, isto é, dois atores principais: a do estudante e a do professor. Essa interação entre uma e outra função configura-se como um jogo em que ambos, ao exercerem suas funções, aprendem e ensinam. Um professor aprende como ensinar e um estudante ensina como aprender. É mesmo um jogo estéticopolítico, pois há aí uma partilha de um sensível, como o define Jacques Rancière:

\begin{abstract}
Denomino partilha do sensível o sistema de evidências sensíveis que revela, ao mesmo tempo, a existência de um comum e dos recortes que nele definem lugares e partes respectivas. Uma partilha do sensível fixa portanto, ao mesmo tempo, um comum partilhado e partes exclusivas. Essa repartição das partes e dos lugares se funda numa partilha de espaços, tempos e tipos de atividade que determina propriamente a maneira como um comum se presta à participação e como uns e outros tomam parte nessa partilha (2009, p. 15).
\end{abstract}

Essa partilha ocorre por meio daquilo que é acessível pela percepção de cada um dos participantes do jogo. Este por sua vez é estético porque demanda percepção e julgamento daquilo que é percebido e, ao mesmo tempo, é político porque é demandado por um conjunto socialmente organizado (a sala de aula, a sala de ensaios no teatro). Esse conjunto é, evidentemente, composto de imagens ou representações sociais e formam, para utilizar uma noção do campo do imaginário, uma "bacia semântica". Para Durand,

\begin{abstract}
A bacia semântica permite a integração das evoluções científicas [...] e, em seguida, uma análise mais detalhada em subconjuntos [...] de uma era e área do imaginário: seu estilo, mitos condutores, motivos pictóricos, temáticas literárias, etc, numa mitoanálise generalizada, isto é, propondo uma "medida" para justificar a mudança mais pertinente do que o menos explícito "princípio dos limites" (2004, p. 103).
\end{abstract}

É a relação desses conjuntos (um apresentado pelo professor, a partir de saberes pessoais, no ato de ensinar, outro constituído por todos os saberes de um estudante, no ato de aprender) que está presente na partilha do sensível. Uma bacia semântica institui as formas mesmas de ensinar/aprender.

Quando se afirma que o teatro é um espaço privilegiado de aprendizagem/ ensino, salienta-se que se trata de um espaço em que mesmo os atores propondo a cena, os espectadores são livres para compreendê-la de um modo particular. É essa interação inevitável ao teatro que o torna um jogo em que seus participantes são livres e autônomos para instituir suas leituras de mundo. Entretanto, como nos lembra Edgar Morin,

A autonomia [...] não é mais uma liberdade absoluta, emancipada de qualquer dependência, mas uma autonomia que depende de seu meio ambiente, seja ele biológico, cultural e social. Assim, um ser vivo, para salvaguardar sua autonomia, trabalha, despende energia, e deve, obviamente, abastecer-se de energia em seu meio, do qual depende. [...] só podemos ser autônomos a partir de uma dependência original em relação à cultura, em relação à língua, em relação a um saber. A autonomia não é possível em termos absolutos, mas em termos relacionais e relativos (2001, p. 118).

A questão da aprendizagem/ensino, 
procurando manter certa autonomia e liberdade nos caminhos da pesquisa, foi cunhada articulando um método que é um espaço de aprendizagem/ensino atento para a partilha do sensível, no sentido de Rancière.

Em vez de pensar a forma-ação de um ator-professor (com hífem), assumi justapor as funções em um atorprofessor. Ao cunhar o termo atorprofessor busquei atentar para o fato de que o teatro, seja qual for a sua forma, pode ser um momento no qual é possível aprender/ensinar. Quis deixar claro que o termo atorprofessor reforça ainda mais o processo educacional que pode ser o teatro, abrindo a cena como espaço de aprendizagem/ensino tanto para o ator quanto para o espectador.

Ao aglutinar as noções de ator e de professor, pretendi deixar claro que a relação entre o trabalho do ator e o trabalho do professor tem a seguinte semelhança: ambos os trabalhos partem de formas e ações. $\mathrm{O}$ encontro entre dois grupos que é o princípio elementar do teatro também está presente em salas de aula. Se há um encontro, há um diálogo e é esse dialogismo que garante a aprendizagem/ ensino de um conjunto de fazeres/saberes específico. Evidentemente guardadas as peculiaridades de cada linguagem.

\section{Último fragmento: a reeducação do sensível}

A reeducação do sensível pode ser amplificada se há a compreensão de que agimos no presente construindo o futuro impregnados de estruturas estruturantes do passado. A ação presentifica a forma, dando vitalidade a ela, dando a ela o frescor do sensível que a compõe. A ação é fruto do presente - é o tempo em sua duração plena, a forma é o elo entre tempo e espaço - são as artimanhas do tempo.

A forma é uma maneira de reconhecer a pluralidade dos mundos, tanto no plano do macrocosmo geral, do cosmos social, quanto no do microcosmo individual, e isto sem deixar de manter a coesão necessária à vida. Assim, sem reduzir à unidade - que é o próprio do racionalismo - ela favorece a unidade, dá coesão a coisas díspares. Em outras palavras, num mundo de contrastes, ela permite que se tenha uma ideia de conjunto: a da organicidade que une, subterraneamente, todos os fragmentos do heterogêneo (MAFFESOLI, 2008, p. 86).

A relação entre forma e ação é um princípio fundante na reeducação do sensível. É mesmo uma movência absoluta: uma forma que estrutura uma ação que é estruturante de uma forma que... E essa complexidade ocorre em um ambiente em que a ambivalência é o fermento principal: o microssocial. Isto é, o cotidiano de cada um de nós. As personagens, as formas que estruturam as ações de um ator são estruturantes na medida em que estimulam suas potencialidades sensíveis naturais.

Operei na tese como a forma enquanto imagens do passado e a ação como presentificação dessas imagens que nos antecederam. As imagens do passado foram criadas no trajeto antropológico da humanidade (enquanto formas sensíveis que se tornam estruturadas) em tensão com trajetos antropológicos específicos (enquanto ações sensíveis estruturantes ou reestruturantes).

$\mathrm{O}$ jogo entre forma e ação, aquilo que venho denominando forma-ação, é resultado de uma dinâmica que tem como elemento tensional aquilo que é sensível: as coisas do mundo, as imagens de todas as ordens que nos afeta sensivelmente. Contudo, o sensível não está apenas no olhar, no cheirar, no tatear, no ouvir, no detectar os azedos, amargos, etc. O sensível quejoga com o imaginário está em uma série de tensões entre as formas e as ações: disso emerge o saborear, o vislumbrar, enfim, o envolver-se com determinada formaação. Ao trabalharmos com personagens, enquanto imagens de possíveis indivíduos, tocamos e somos tocado por elas.

Tomo como exemplo a noção de teatro. $O$ teatro significa coisas diferentes para cada indivíduo ou coletivos de pessoas. $\mathrm{O}$ 
mesmo acontece com a noção de educação. Entender uma noção está na dependência da qualidade da tensão entre as formas estruturadas e as ações estruturantes. $\mathrm{O}$ que determina o entendimento que um indivíduo tem de teatro, educação, medicina, história, etc, é o conjunto de imagens anteriores em relação às imagens do presente. As imagens anteriores formam o arcabouço do imaginário, as imagens do presente concretizam o espaço de construção dos sentidos.

\section{Referências bibliográficas}

BACHELARD, Gaston. A poética do espaço. São Paulo: Martins Fontes, 1993.

DE MARINIS, Marco. La parábola de Grotowski: el secreto del "novecento" teatral. Buenos Aires: Galerna/GETEA, 2004.

DURAND, Gilbert. As estruturas antropológicas do imaginário: introdução à arquetipologia geral. São Paulo: Martins Fontes, 2002.

DURAND, Gilbert. O imaginário: ensaio acerca das ciências e da filosofia da imagem. Rio de Janeiro: DIFEL, 2004.

GADAMER, Hans-Georg. Verdade e Método I - traços fundamentais de uma hermenêutica filosófica. Petrópolis/Bragança Paulista: Vozes/Ed. Universitária São Francisco, 2004.

GALEANO, Eduardo. O livro dos abraços. Porto Alegre: L\&PM, 2007.

GROTOWSKI, Jerzy. Em busca de um teatro pobre. Rio de Janeiro: Civilização Brasileira, 1992.

GROTOWSKI, Jerzy \& FLASZEN, Ludwik. O Teatro Laboratório de Jerzy Grotowski 19591969. São Paulo: Perspectiva, 2007.

MAFFESOLI, Michel. Elogio da razão sensível. Petrópolis: Editora Vozes, 2008.

MÁSCARA - Cuaderno Iberoamericano de reflexión sobre escenología. Cieslak. Ano IV, n¹6. México: Escenología, 1994.

MORIN, Edgar. A cabeça bem-feita: repensar a reforma reformar o pensamento. Rio de
Janeiro: Bertrand Brasil, 2001.

RANCIÈRE, Jacques. O inconsciente estético. São Paulo: Editora 34, 2009.

RICHARDS, Thomas. Trabajar con Grotowski sobre las acciones físicas. Barcelona: Alba Editorial, 2005.

STANISLAVSKI, Constantin. A criação de um papel. Rio de Janeiro: Civilização Brasileira, 1984.

- Minha vida na arte. Rio de Janeiro:

Civilização Brasileira, 1989.

A preparação do ator. Rio de Janeiro:

Civilização Brasileira, 2005.

A construção da personagem. Rio de Janeiro: Civilização Brasileira, 2006.

TAKEDA, Cristiane Layher. O cotidiano de uma lenda - cartas do Teatro de Arte de Moscou. São Paulo: Perspectiva, 2003. 